\title{
Anti Inflammatory Effects of Statins in Cardiac Surgery Patients*
}

\author{
Adnan Raza, ${ }^{1,2 \#}$, Susan Kennedy ${ }^{2}$, Yue Fan ${ }^{2}$, Belinda Maher ${ }^{2}$, Mary Codd $^{2}$, \\ Thomas Murphy ${ }^{2}$, Alfred Wood ${ }^{1}$, William Watson ${ }^{2}$ \\ ${ }^{1}$ Eoin O’Malley National Centre for Cardiothoracic Surgery, Mater Misericordiae University Hospital, Dublin, Ireland \\ ${ }^{2}$ UCD School of Medicine and Medical Sciences, Conway Institute, University College Dublin, Dublin, Ireland \\ Email: \#adnan_raza@hotmail.com
}

Received May 16, 2012; revised June 30, 2012; accepted July 18, 2012

\begin{abstract}
Objectives: Cardiac surgery with cardiopulmonary bypass provokes systemic inflammatory response, which may cause organ dysfunction. Studies have suggested that pre-operative statin therapy can reduce morbidity and mortality associated with cardiac surgery; the mechanism for this remains unclear. We hypothesise that underlying mechanism of action for these effects of statins is through inhibition of neutrophil transendothelial migration. Methods: We recruited 151 patients undergoing cardiac surgery. Of these 41 patients were on no-statin; 48 patients on low-dose (10 - $30 \mathrm{mg})$ and 62 patients were on high-dose statin $(40-80 \mathrm{mg})$. Ex vivo neutrophil migration was performed on pre-operative blood samples of 90 patients. Of these 90 patients we used 36 patients to assess the levels of TNF- $\alpha$ and sICAM-1. Clinical parameters of total 151 patients were assessed to analyse outcome. Results: Ex vivo neutrophil migration was decreased in high-dose statin group when compared to neutrophils isolated from no-statin or low-dose statin groups $(\mathrm{p}<0.001)$. Serum TNF- $\alpha$ levels were lower in the high-dose statin group $(p=0.002)$ and sICAM-1 levels were decreased in both low $(p=0.02)$ and high-dose statin $(p=0.01)$ groups. Conclusion: Our study demonstrates that high-dose statins reduce ex-vivo transendothelial neutrophil migration, TNF- $\alpha$ and sICAM-1 serum levels suggesting that statins may help in decreasing the post-cardiac surgery morbidity.
\end{abstract}

Keywords: Statins; Neutrophils; Cardiac Surgery; Outcome; TNF- $\alpha$; sICAM-1

\section{Introduction}

Cardiac surgery with extracorporeal circulation is associated with neutrophil activation, inflammation and oedema, which may lead to organ dysfunction [1]. The most undesirable effect of cardiopulmonary bypass (CPB) is the systemic inflammatory response syndrome (SIRS) [2]. Multiple factors are involved in initiating SIRS, which include exposure of blood to non-physiologic surfaces, surgical trauma, ischemia-reperfusion injury, changes to body temperature and release of endotoxins. All these factors are well established to induce complex inflammatory responses including complement activation, release of cytokines, leukocyte activation and production of various substances like oxygen free radicals, arachidonic acid metabolites, platelet activating factors and endothelins [3]. These inflammatory cascades can lead to the development of post operative complications like renal dysfunction, respiratory failure, neurological dysfunction or ultimately

${ }^{*}$ Conflicts of Interest: None declared.

${ }^{\#}$ Corresponding author. multi organ dysfunction.

Neutrophils are activated in response to inflammatory stimuli, trauma or surgery. After being stimulated, neutrophils migrate out of the blood stream to the site of inflammation or trauma. Neutrophil transmigration into tissue is a multistep process that results from coordinated rearrangement of the cytoskeleton and adhesion complexes. Chemotactic factors bind to transmembrane receptors and activate G-proteins; after which complex interrelated signalling pathways are activated [4]. Rho GTPases regulate a wide range of fundamental cell functions and play an important role in neutrophil transmigration. Statins inhibit Rho activity and as a result lead to inhibition of neutrophil migration $[4,5]$.

Statins or Hydroxymethylglutaryl coenzyme A (HMG$\mathrm{CoA})$ reductase inhibitors are potent cholesterol-lowering drugs. Statins are the most studied drugs available today. Like all medication, statins have potential side effects that are usually mild, easy to recognize, reversible and very rarely dangerous. Statins can also lead to liver dysfunction and the incidence of this abnormality with dif- 
ferent statins is less than 3\% [6]. Statins beneficially regulate atherogenesis, plaque stability and myocardial ischemia in significant coronary artery disease by influencing lipid metabolism and intracellular signalling pathways other than cholesterol [7]. Their efficacy in reducing morbidity and mortality associated with cardiovascular events has been demonstrated in a number of clinical studies $[7,8]$. One of the key effects of statins appears to be inhibition of leukocyte-endothelium interaction. This effectively attenuates the infiltration of leukocytes (particularly neutrophils) into inflamed regions, thus curtailing tissue injury in these areas. The mechanisms of this off-target effect may be both cellular and non-cellular.

Tumor necrosis factor alpha (TNF- $\alpha$ ) is an important pro-inflammatory cytokine and potent chemoattractant for neutrophils by inducing the expression of adhesive molecules on the endothelial cells and facilitating their adherence [9]. Inter-Cellular adhesion molecule 1 (ICAM1), a member of adhesion molecules, also plays an important role in the regulation of adhesion and migration of all types of inflammatory cells [10]. It has been demonstrated that the in vitro and in vivo expression of ICAM-1 on endothelial cells is up regulated by cytokines like TNF- $\alpha$ and interleukin-1 [11]. Studies have also shown that statin treatment decreases the levels of TNF- $\alpha$ and ICAM-1 [12,13]. In view of these previous studies we hypothesized that the use of statins pre-operatively may inhibit neutrophil migration and lower circulating levels of TNF- $\alpha$ and sICAM-1, reducing inflammatory responses and can result in a better clinical outcome.

\section{Materials and Methods}

\subsection{Ethical Approval}

Approval was obtained from the Mater Misericordiae University Hospital Ethics Committee and informed consent was obtained from patients undergoing open heart surgery.

\subsection{Patient Recruitment and Blood Sample Collection}

We prospectively recruited 151 consecutive patients. Blood samples were collected from first 90 patients to perform neutrophil migration and additional 61 patients were then recruited for assessment of in-hospital clinical outcome. We analysed the pre operative levels of TNF- $\alpha$ and sICAM-1 in 36 patients undergoing open heart surgery who were matched for pre-operative clinical factors including age, associated co-morbidities and procedure. Based on the pre-operative statin usage patients were divided into three groups, non-statin $(n=41)$, low-dose statin $(10-30 \mathrm{mg})(\mathrm{n}=48)$ and high-dose statin $(40-80$ $\mathrm{mg})(\mathrm{n}=62)$. Patients on antibiotics, anti inflammatory medication or steroids or undergoing emergency surgery were excluded from the study.

\subsection{Neutrophil Isolation}

Neutrophils were isolated from (pre-operative) venous blood samples by Dextran (3\%) sedimentation and centrifuged through a discontinuous ficoll gradient, as described by Maher et al. [5].

\subsection{Collagen Coating of Transwell Filters}

Human type IV collagen (Sigma-Aldrich) was diluted 1 in 10 with $0.25 \%$ acetic acid solution to give a working stock solution of $50 \mu \mathrm{g} / \mathrm{ml}$. Of this solution, $50 \mu \mathrm{l}$ was added to each Transwell polycarbonate membrane filter (6.5 mm diameter, $3.0 \mu \mathrm{m}$ pore size, Corning Costar). The collagen was allowed to air-dry overnight in a laminar airflow cabinet with airflow switched on. On the following day, filters were seeded with Human pulmonary artery endothelial cells (HPAECs) as described below.

\subsection{Cell Culture}

HPAECs, (Cambrex) were cultured in 100\% humidity and $5 \% \mathrm{CO}_{2}$ at $37^{\circ} \mathrm{C}$ in endothelial growth medium supplemented with $5 \%$ foetal bovine serum, epidermal growth factor $(10 \mathrm{ng} / \mathrm{ml})$, hydrocortisone $(1 \mu \mathrm{g} / \mathrm{ml})$, bovine brain extract $(10 \mu \mathrm{g} / \mathrm{ml})$ and gentamicin $(50 \mu \mathrm{g} / \mathrm{ml})$. When approximately $80 \%$ confluent, cells were harvested, resuspended in fresh medium and seeded at a concentration of $0.1 \times 10^{6}$ cells in $200 \mu$ l onto Transwell polycarbonate membrane filters $(6.5 \mathrm{~mm}$ diameter, $3.0 \mu \mathrm{m}$ pore size, Corning Coster) that had been coated with human type IV collagen. Culture medium, $600 \mu \mathrm{l}$ was added to the lower compartment and the cells were cultured for a further 4 days. All experiments were carried out on HPAECs between passages 6 to 10 .

\subsection{Transendothelial Migration Assay}

The transmigration assay utilized in these experiments was developed by Mackarel et al. [14]. After 4 days in culture, HPAECs on the Transwell filter inserts were transferred to a fresh 24-well tissue culture plate. Culture medium was carefully removed from filters and after gentle rinsing of the cells with Hank's balanced salt solution (HBSS) pre-warmed to $37^{\circ} \mathrm{C}$, medium was replaced with $100 \mu \mathrm{l}$ of Dulbecco's modified eagle's medium (DMEM).

Prior to the addition of neutrophils to the apical compartment of the system, $600 \mu \mathrm{l}$ of DMEM (control) or Formyl-Methionyl-Leucyl-Phenylalanine (fMLP) $10^{-8} \mathrm{M}$ in DMEM was added to the basolateral compartment and the plate was incubated for 45 minutes at $37^{\circ} \mathrm{C}$ in the incubator. Isolated neutrophils were re-suspended at a concentration of $1 \times 10^{7}$ per ml. $100 \mu \mathrm{l}$ of neutrophil cell 
suspension $\left(1 \times 10^{6}\right)$ was added to each filter to initiate the migration assay. Once the neutrophils were added, an extra $100 \mu \mathrm{l}$ of DMEM or fMLP $\left(10^{-8} \mathrm{M}\right)$ was added to the basal compartment to equalize the liquid levels of the apical and basolateral compartments. Transwell filters were incubated for 3 hours at $37^{\circ} \mathrm{C}$ in humidified $\mathrm{CO}_{2}$ incubator after which plate were placed on ice. Non-migrated and migrated neutrophils were separated by lifting the filter inserts out of the well in which they have been suspended. Any migrated neutrophils loosely bound to the under surface of the filter were added into the migrated neutrophils in the lower compartment to the Transwell. Both populations of neutrophils were collected by centrifugation at $1300 \mathrm{rpm}$ for 10 minutes at $4^{\circ} \mathrm{C}$. The neutrophils were then lysed in $0.25 \%$ Brij. To harvest the filter samples and attached neutrophils, the filter inserts were cut out using a sharp scalpel and lysed with $0.25 \%$ Brij detergent. All lysates were then assayed for myleoperoxidase (MPO) activity. Briefly the $\mathrm{pH}$ of neutrophil lysates was adjusted to 4.2 by the addition of $100 \mathrm{mM}$ citrate buffer. Aliquotes of each sample were then transferred to a 96 well plate and incubated for 10 minutes with $100 \mu \mathrm{l}$ of $2 \mathrm{mM}$ ABTS in $100 \mathrm{mM}$ citrate buffer, $\mathrm{pH}$ 4 . containing $0.06 \% \mathrm{H}_{2} \mathrm{O}_{2}$. The reaction was then stopped by the addition of $2 \%$ sodium dodecyl sulphate. Absorbance was measured at $405 \mathrm{~nm}$ using a Microplate EL 309 Autoreader (Bio-tek Instruments, Inc., Winooski, VT).

\subsection{Tumor Necrosis Factor Alpha (TNF- $\alpha$ ) and sICAM-1 Analysis}

At the time of neutrophil isolation, serum samples were stored at $-80^{\circ} \mathrm{C}$ and thawed just before the analysis. TNF$\alpha$ and sICAM-1 levels were measured by the use of enzyme linked immune-sorbent assay (ELIZA kits by R\&D Systems, UK).

\subsection{Statin Pre-Treatment}

Clinical outcome data was collected from 90 patients recruited as a part of the neutrophil migration study and an additional 61 patients were recruited consecutively who were admitted for planned cardiac surgery. Statin pretreatment occurred in 110 patients who were compared with non-statin group $(\mathrm{n}=41)$. Out of 110 patients who were on statins, $86.4 \%$ were on atorvastatin, $7.3 \%$ were on pravastatin, $3.6 \%$ were on simvastatin and only $2.7 \%$ were on rosuvastatin. Minimum duration of statin therapy was 6 weeks. We assessed and ensured at the time of recruitment that the patients on statins were tolerating the medicine well, had no signs/symptoms of side effects (including liver dysfunction) and had no compliance issues. Pre-operative parameters included; age, gender, pre operative co-morbidities like recent history of myocardial infarction (MI) in the past 90 days, diabetes mellitus
(DM), peripheral vascular disease (PVD) and renal impairment. Other pre-operative factors included left ventricular ejection fraction of heart and EuroSCORE [15]. Post operative factors included laboratory parameters including white cell count (WCC) at day 1, 3 and 5; similarly serum creatinine levels at day 1,3 and 5 were determined to assess underlying renal function. Other factors included Intensive Care Unit (ICU) stay, post operative hospital stay, post operative dialysis and mortality.

\subsection{Statistical Analysis}

Statistical analysis was performed by using SPSS 15.0. Normal distributed or non-parametric data was determined by conducting Shapiro normality, Dago normality and Anderson Darling normality tests. Normally distributed data was analysed by using t test and ANOVA as appropriate. Non parametric data was analysed by using Mann Whitney U or Kruskal Wallis test as appropriate. For categorical data analysis chi-square test was applied. A p value of $<0.05$ was considered to be significant.

\section{Results}

\subsection{Effects of Statins on Neutrophil Transendothelial Migration}

Neutrophil migration across collagen-coated filters was performed on consecutive 90 patients (Non-statin: $\mathrm{n}=24$; low-dose statin: $\mathrm{n}=31$ and high-dose statin: $\mathrm{n}=35$ ).

Neutrophils isolated from the high-dose statin group had significantly $(\mathrm{p}<0.001)$ lower migration $(3.4 \% \pm 1.4 \%)$ than the non-statin group $(6.8 \% \pm 2.7 \%)$ and low-dose statin group $(5.9 \% \pm 2.3 \%)$ (Figure 1). There was no significant difference between non-statin and low-dose statin groups $(\mathrm{p}=0.308)$. The analysis was appropriately powered by using $\mathrm{t}$ test showing sample size of 12.2 ( $\mathrm{p}=$ 0.05 ) for non-statin and high-dose statin groups.

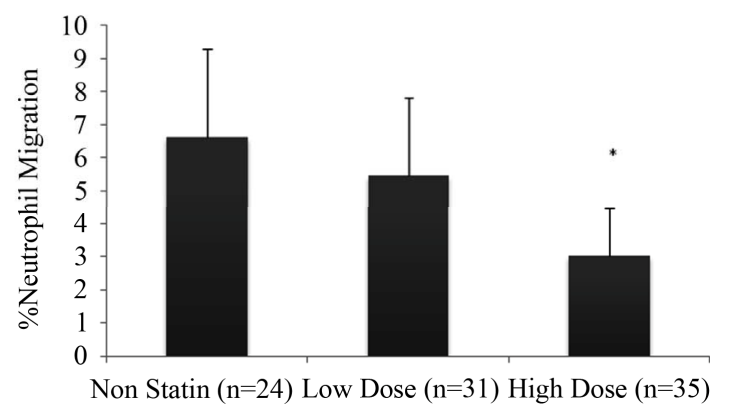

Figure 1. Effects of statins on neutrophil migration. Neutrophils were isolated from three patients groups and migrated across endothelial cells in response to fMLP $\left(10^{-8} \mathrm{M}\right)$ as described in material and methods section. Results are mean \pm SD for the three groups respectively. *p $<0.01$ vs non statin group, statistical analysis carried out by using ANOVA. 


\subsection{Effects of Statins on Serum TNF- $\alpha$ and sICAM-1 Levels}

We analysed the pre operative levels of TNF- $\alpha$ and sICAM-1 in a matched group of 36 patients undergoing open heart surgery. Non-statin group $(\mathrm{n}=12)$ results showed mean TNF- $\alpha$ concentration of $10.2 \pm 1.8$, lowdose statin group $(\mathrm{n}=12): 9.4 \pm 2.7$ and high-dose statin group $(\mathrm{n}=12): 7.5 \pm 1.8$ (Figure 2 ). There was no significant difference between non-statin and low-dose statin groups $(\mathrm{p}=0.37)$ or low-dose and high-dose statin groups $(\mathrm{p}=0.08)$, however there was a significant difference between non-statin and high-dose statin groups $(p=0.002)$. sICAM-1 analysis revealed high levels of concentration in the non-statin group $(\mathrm{n}=12): 68.8 \pm 6.9$ as compared to low-dose statin $(\mathrm{n}=12): 60.6 \pm 9.5$ and high-dose statin groups $(n=12): 58.8 \pm 9.8$ (Figure 2). There was a significant difference between non-statin and low-dose statin groups $(\mathrm{p}=0.02)$ and non-statin and high-dose statin groups $(p=0.01)$. The analysis was appropriately pow- ered by using ANOVA showing $\mathrm{p}=0.0183$ for $\mathrm{TNF}-\alpha$ and $\mathrm{p}=0.0097$ for sICAM-1.

\subsection{Effects of Statins on In-Hospital Clinical Outcome Post Cardiac Surgery}

Patients in the high-dose statin group were older in age group $(66.6 \pm 9.46$ years $)$, had significant history of MI $(\mathrm{n}=31,50 \%)$ and significant history of peripheral vascular disease $(\mathrm{n}=21,51 \%)$ as compared to the non-statin group who were comparatively younger in age (57.8 \pm 18.8 years) and had no significant history of $\mathrm{MI}(\mathrm{n}=5$, $12 \%)$ or PVD $(n=4,10 \%)$. There was no difference in history of renal impairment, left ventricular ejection fraction and EuroSCORE between the groups (Table 1). Results from non-statin group vs high-dose statin group showed the rate of MI $(12 \%$ vs $50 \%, \mathrm{p}<0.001)$, PVD $(10 \%$ vs $51 \%, \mathrm{p}=0.005), \mathrm{DM}(12 \%$ vs $24 \%, \mathrm{p}=0.132)$ and age (Mean 57.8 vs 66.6, $\mathrm{p}=0.025$ ).

There was no difference identified in factors like op-
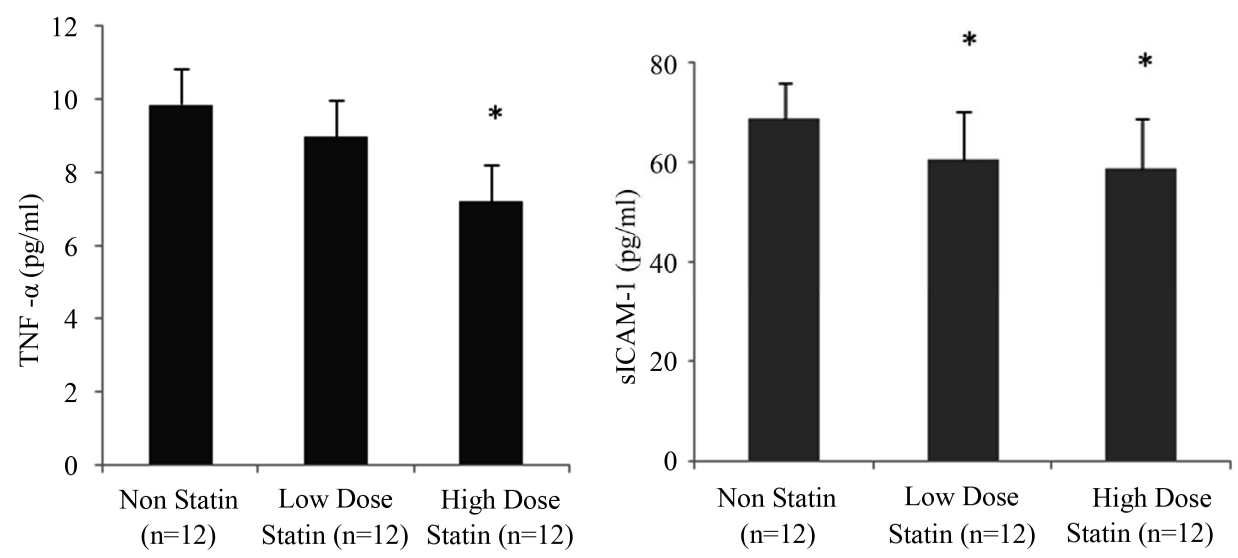

Figure 2. Effects of statins on TNF- $\alpha$ (left) and sICAM-1 (right) levels. Serum samples isolated from the three patient groups $(n=36)$ and assessed by ELIZA in accordance to the material and methods section. Values expressed as mean \pm SD. *p $<0.05$ is considered significant vs the non-statin group.

Table 1. Comparison of pre-operative variables in all three groups.

\begin{tabular}{|c|c|c|c|c|c|c|}
\hline Pre-Operative Variables & $\begin{array}{l}\text { Non-Statin } \\
(\mathrm{n}=41)\end{array}$ & $\begin{array}{l}\text { LD-Statin } \\
(\mathrm{n}=48)\end{array}$ & $\begin{array}{l}\text { HD-Statin } \\
(\mathrm{n}=62)\end{array}$ & $\begin{array}{l}\mathrm{p} \text { Value } \\
\text { Anova }\end{array}$ & $\begin{array}{l}\mathrm{p} \text { Value } \\
\text { Chi Sq }\end{array}$ & $\begin{array}{c}\mathrm{p} \text { Value } \\
\mathrm{K} \text {-Wallis }\end{array}$ \\
\hline \multirow[t]{2}{*}{ Age (yrs) Mean(SD) } & $57.8(18.8)$ & $63.9(7.95)$ & $66.6(9.46)$ & - & - & 0.05 \\
\hline & $\mathrm{n}(\%)$ & $\mathrm{n}(\%)$ & $\mathrm{n}(\%)$ & & & \\
\hline Gender: Male & $25(61 \%)$ & $36(75 \%)$ & $50(81 \%)$ & - & & \\
\hline Female & $16(39 \%)$ & $12(25 \%)$ & $12(19 \%)$ & - & 0.062 & - \\
\hline History of MI & $05(12 \%)$ & $18(37.5 \%)$ & $31(50 \%)$ & - & 0.000 & - \\
\hline History of DM & $05(12 \%)$ & $11(23 \%)$ & $15(24 \%)$ & - & 0.296 & - \\
\hline History of PVD & $04(10 \%)$ & $8(19.5 \%)$ & $21(51 \%)$ & - & 0.007 & - \\
\hline History of Renal Disease & $11(27 \%)$ & $8(17 \%)$ & $9(14.5 \%)$ & - & 0.272 & - \\
\hline
\end{tabular}


Continued

\begin{tabular}{rccccc}
\hline Ejection Fraction: Good & $27(66 \%)$ & $25(52 \%)$ & $32(52 \%)$ & & 0.573 \\
Fair & $10(24 \%)$ & $17(35 \%)$ & $24(39 \%)$ & - & - \\
Poor & $04(10 \%)$ & $06(13 \%)$ & $06(10 \%)$ & & - \\
EuroScore Mean (SD) & $6(3.01)$ & $5.43(5.37)$ & $5.90(3.26)$ & 0.282 & - \\
Logestic EuroScore Mean (SD) & $7.78(8.34)$ & $7.25(9.05)$ & $7.66(7.69)$ & - & - \\
\hline
\end{tabular}

Table 1: Normally distributed data of all three groups was analysed by using ANOVA and non parametric data by Kruskal Wallis test. For categorical data analysis chi-square test was applied. A p value of $<0.05$ was considered to be significant. HD-statin $=$ High dose statin; LD-Statin $=$ Low dose statin; $(-)=$ Not applicable; MI = Myocardial Infarction; DM = Diabetes Mellitus; PVD = Peripheral Vascular Disease.

eration priority and use of intra-aortic balloon pump (IABP) between all the three groups. Patients in non-statin group mainly underwent valve surgery $\{\mathrm{n}=24(58 \%), \mathrm{p}<0.001\}$ as compared to the low-dose statin group $\{\mathrm{n}=5(10 \%)\}$ and high-dose statin group $\{\mathrm{n}=10(16 \%)\}$ but there was no difference in cardiopulmonary bypass time or aortic cross clamp (x-clamp) time between all the three groups (Table 2).

No statistically significant difference in serum white cell count (WCC) and serum creatinine levels at days 1, 3 and 5 was found. Similarly when applying multivariate analysis no difference was noticed in Intensive Care Unit (ICU) stay. The post operative hospital stay of high dose statin group was lower 10 (6 - 27) days when compared to non-statin group, 12 (7 - 32) and low dose statin group, 11 (5 - 26) days, however it did not reach statistical significance (Tables 3 and 4). Similarly there was no difference in post operative dialysis $(p=0.471$ by chi sq test and 0.532 by Fisher's exact test) and mortality.

\section{Discussion}

CPB can lead to postoperative complications like SIRS. These changes are associated with a risk of post-operative organ dysfunction and increased morbidity and mortality in the postoperative period $[8,16]$. We have previously demonstrated that statins inhibit neutrophil migration in vitro by specific inhibition of Rho activity [5].

In this study we have illustrated the in vivo effects of statins on transendothelial neutrophil migration. We have established that high dose statins inhibit ex vivo transendothelial neutrophil migration and also attenuate the leukocyte-endothelium interaction by altering the levels of TNF- $\alpha$ and sICAM-1. We demonstrated that high dose statins $(40-80 \mathrm{mg}$ ) reduce neutrophil transendothelial migration significantly as compared to the lower dose (10 - $30 \mathrm{mg}$ ) or non-statin groups (Figure 1).

We noted that patients in the non-statin group were younger in age and had less co-morbidities as compared to patients in the low dose and high dose statin groups; which might create a biasness in the patient selection and procedure and may have affected the neutrophil migration results. However, this might be clarified when we look at patients in the low and high dose statin groups.
They were of the same age, had similar co-morbidities and underwent the same procedure; but still there was a significant difference in their neutrophil migration.

A recently published study has shown that statin therapy improves outcome after valvular heart surgery [17]. It has been demonstrated in another study that the use of statins in healthy volunteers significantly reduces neutrophil migration within two weeks of therapy [18]. Unlike many studies, our patient population was not restricted to patients undergoing coronary artery bypass grafting (CABG) only but also included patients undergoing valve repair or replacement procedure and combination of both (CABG + Valve Procedure). This increases the generalizability of our findings and might also indicate that effect of statin pre-treatment is not influenced by cardiac disease but influences more intrinsic biologic process. This confirms that effects of statins on neutrophil migration are independent of the patient or procedure related factors.

We have demonstrated in a sub-group of patients with statistically similar age and pre-operative factors including operative procedure that high dose statins inhibited preoperative TNF- $\alpha$ levels compared to the non-statin and low dose statin groups (Figure 2).

Soluble ICAM-1 can reflect the inflammatory activity and can be used as an indirect measure of endothelial ICAM-1 levels [19]. Studies have shown the ICAM-1 expression on endothelial cells is up-regulated by TNF- $\alpha$ and other cytokines [11]. We observed that level of sICAM-1 was higher in the non-statin group as compared to low dose statin and high dose statin groups (Figure 2). These findings suggest that statins modulate the expression of TNF- $\alpha$, which in turn directly or indirectly alters the function of sICAM-1, leading to decreased leukocyteendothelium interaction and ultimately attenuate the migration process.

We assessed patient's outcome following open heart surgery in total 151 patients and observed that patients referred for cardiac surgery had a high incidence of pre-existing co-morbidities such as Diabetes Mellitus (DM), peripheral vascular disease (PVD) and history of myocardial infarction (MI). Also, the age of patients referred for cardiac surgery has increased in the recent years, which leads to limited physiological reserves within their 
Table 2. Comparison of operative variables in all three groups.

\begin{tabular}{|c|c|c|c|c|c|c|}
\hline Operative Variables & $\begin{array}{l}\text { Non-Statin } \\
(\mathrm{n}=41)\end{array}$ & $\begin{array}{l}\text { LD-Statin } \\
(\mathrm{n}=48)\end{array}$ & $\begin{array}{l}\text { HD-Statin } \\
(\mathrm{n}=62)\end{array}$ & $\begin{array}{l}\mathrm{p} \text { Value } \\
\text { Anova }\end{array}$ & $\begin{array}{l}\mathrm{p} \text { Value } \\
\text { Chi Sq }\end{array}$ & $\begin{array}{l}\mathrm{p} \text { Value } \\
\text { K-Wallis }\end{array}$ \\
\hline & $\mathrm{n}(\%)$ & $\mathrm{n}(\%)$ & $\mathrm{n}(\%)$ & & & \\
\hline $\begin{array}{c}\text { Operative Priority: Elective } \\
\text { Urgent }\end{array}$ & $\begin{array}{l}19(46 \%) \\
22(54 \%)\end{array}$ & $\begin{array}{l}14(29 \%) \\
34(71 \%)\end{array}$ & $\begin{array}{l}19(31 \%) \\
43(69 \%)\end{array}$ & - & 0.170 & - \\
\hline $\begin{array}{c}\text { Procedure: } \text { CABG } \\
\text { Valve Surgery } \\
\text { Combination }\end{array}$ & $\begin{array}{l}05(12 \%) \\
24(58 \%) \\
12(30 \%)\end{array}$ & $\begin{array}{l}30(62 \%) \\
05(10 \%) \\
13(28 \%)\end{array}$ & $\begin{array}{l}39(63 \%) \\
10(16 \%) \\
13(21 \%)\end{array}$ & - & 0.001 & - \\
\hline IABP & $04(09 \%)$ & $05(10 \%)$ & $05(10 \%)$ & - & 0.529 & - \\
\hline $\begin{array}{l}\text { Bypass Time: } \text { Median } \\
\text { (mins) }\end{array}$ & $\begin{array}{c}94 \\
(42-242)\end{array}$ & $\begin{array}{c}96 \\
(45-147)\end{array}$ & $\begin{array}{c}101 \\
(42-294)\end{array}$ & & & 0.113 \\
\hline $\begin{array}{l}\text { X-Clamp Time: } \text { Median } \\
\text { (mins) }\end{array}$ & $\begin{array}{c}59 \\
(26-119)\end{array}$ & $\begin{array}{c}54 \\
(25-110)\end{array}$ & $\begin{array}{c}65 \\
(31-143)\end{array}$ & 0.060 & - & - \\
\hline
\end{tabular}

Table 2: Normally distributed data of all three groups was analysed by using ANOVA and non parametric data by Kruskal Wallis test. For categorical data analysis chi-square test was applied. A $p$ value of $<0.05$ was considered to be significant. Mins $=$ minutes. $\mathrm{CABG}=\mathrm{Coronary}$ Artery Bypass Grafting; IABP $=$ Intra Aortic Balloon Pump; Combination = CABG + Valve Surgery; X-Clamp = Cross Clamp Time.

Table 3. Comparison of post-operative variables in all three groups.

\begin{tabular}{|c|c|c|c|c|c|c|}
\hline Post-Operative Variables & $\begin{array}{l}\text { Non-Statin } \\
(\mathrm{n}=41)\end{array}$ & $\begin{array}{l}\text { LD-Statin } \\
(\mathrm{n}=48)\end{array}$ & $\begin{array}{l}\text { HD-Statin } \\
(\mathrm{n}=62)\end{array}$ & $\begin{array}{l}\mathrm{p} \text { Value } \\
\text { Anova }\end{array}$ & $\begin{array}{l}\mathrm{p} \text { Value } \\
\text { Chi Sq }\end{array}$ & $\begin{array}{l}\mathrm{p} \text { Value } \\
\mathrm{K} \text {-Wallis }\end{array}$ \\
\hline $\begin{array}{r}\text { Pre-Op Creatinine }(\mu \mathrm{mol} / \mathrm{L}): \text { Median } \\
\text { Range }\end{array}$ & $\begin{array}{c}100 \\
(59-289)\end{array}$ & $\begin{array}{c}95 \\
(57-193)\end{array}$ & $\begin{array}{c}91.5 \\
(55-157)\end{array}$ & - & - & 0.543 \\
\hline $\begin{array}{r}\text { Day } 1 \text { Creatinine }(\mu \mathrm{mol} / \mathrm{L}): \text { Median } \\
\text { Range }\end{array}$ & $\begin{array}{c}97 \\
(62-512)\end{array}$ & $\begin{array}{c}92 \\
(64-177)\end{array}$ & $\begin{array}{c}101.9 \\
(55-213)\end{array}$ & - & - & 0.434 \\
\hline $\begin{array}{r}\text { Day } 3 \text { Creatinine }(\mu \mathrm{mol} / \mathrm{L}) \text { : Median } \\
\text { Range }\end{array}$ & $\begin{array}{c}91 \\
(54-451)\end{array}$ & $\begin{array}{c}91 \\
(51-327)\end{array}$ & $\begin{array}{c}96 \\
(45-384)\end{array}$ & - & - & 0.816 \\
\hline $\begin{array}{r}\text { Day } 5 \text { Creatinine }(\mu \mathrm{mol} / \mathrm{L}) \text { : Median } \\
\text { Range }\end{array}$ & $\begin{array}{c}88 \\
(58-305)\end{array}$ & $\begin{array}{c}98 \\
(62-264)\end{array}$ & $\begin{array}{c}91.5 \\
(50-391)\end{array}$ & - & - & 0.952 \\
\hline $\begin{array}{r}\text { Pre-op WCC: } \begin{array}{c}\text { Median } \\
\text { Range }\end{array}\end{array}$ & $\begin{array}{c}7.42 \\
(3.9-10.9)\end{array}$ & $\begin{array}{c}8.13 \\
(4.4-11.6)\end{array}$ & $\begin{array}{c}7.80 \\
(3.7-14.2)\end{array}$ & 0.525 & - & - \\
\hline $\begin{array}{r}\text { Day } 1 \text { WCC: Median } \\
\text { Range }\end{array}$ & $\begin{array}{c}10.6 \\
(6.3-25.7)\end{array}$ & $\begin{array}{c}10.8 \\
(5.0-17.5)\end{array}$ & $\begin{array}{c}10.4 \\
(5.8-20.5)\end{array}$ & - & - & 0.498 \\
\hline $\begin{array}{c}\text { Day } 3 \text { WCC: Median } \\
\text { Range }\end{array}$ & $\begin{array}{c}10.32 \\
(4.6-26.37)\end{array}$ & $\begin{array}{c}9.5 \\
(2.6-25.8)\end{array}$ & $\begin{array}{c}10.7 \\
(5.1-22.5)\end{array}$ & - & - & 0.243 \\
\hline $\begin{array}{c}\text { Day } 5 \text { WCC: Median } \\
\text { Range }\end{array}$ & $\begin{array}{c}8.4 \\
(6.02-21.81)\end{array}$ & $\begin{array}{c}8.9 \\
(4.8-16.5)\end{array}$ & $\begin{array}{c}9.5 \\
(4.9-23.5)\end{array}$ & - & - & 0.637 \\
\hline
\end{tabular}

Table 3: Normally distributed data of all three groups was analysed by using ANOVA and non parametric data by Kruskal Wallis test. For categorical data analysis chi-square test was applied. A $p$ value of $<0.05$ was considered to be significant. $\mu \mathrm{mol} / \mathrm{L}=$ micromoles per litre; Pre-op $=$ Pre-operative; WCC $=$ White Cell Count. 
Table 4. Comparison of post-operative variables in all three groups.

\begin{tabular}{|c|c|c|c|c|c|c|}
\hline Post-Operative Variables & $\begin{array}{l}\text { Non-Statin } \\
(\mathrm{n}=41)\end{array}$ & $\begin{array}{l}\text { LD-Statin } \\
(\mathrm{n}=48)\end{array}$ & $\begin{array}{l}\text { HD-Statin } \\
(\mathrm{n}=62)\end{array}$ & $\begin{array}{l}\mathrm{p} \text { Value } \\
\text { Anova }\end{array}$ & $\begin{array}{l}\mathrm{p} \text { Value } \\
\text { Chi Sq }\end{array}$ & $\begin{array}{c}\mathrm{p} \text { Value } \\
\mathrm{K} \text {-Wallis }\end{array}$ \\
\hline $\begin{array}{l}\text { ICU Days: Median } \\
\text { Range }\end{array}$ & $\begin{array}{c}1 \\
(1-13)\end{array}$ & $\begin{array}{c}1 \\
(1-26)\end{array}$ & $\begin{array}{c}1 \\
(1-7)\end{array}$ & - & - & 0.915 \\
\hline $\begin{array}{c}\text { Post-Op Stay: Median } \\
\text { Range }\end{array}$ & $\begin{array}{c}12 \\
(7-32)\end{array}$ & $\begin{array}{c}09 \\
(5-26)\end{array}$ & $\begin{array}{c}10 \\
(6-27)\end{array}$ & - & - & 0.349 \\
\hline Post-Op Dialysis n (\%) & $06(15 \%)$ & $03(06 \%)$ & $04(06 \%)$ & - & 0.471 & - \\
\hline Destination: Home & $27(66 \%)$ & $28(58 \%)$ & $42(68 \%)$ & & & \\
\hline Care & $13(32 \%)$ & $19(40 \%)$ & $19(30 \%)$ & - & 0.957 & - \\
\hline 30 Day Mortality & $01(02 \%)$ & $01(02 \%)$ & $01(01 \%)$ & & & \\
\hline
\end{tabular}

Table 4: Normally distributed data of all three groups was analysed by using ANOVA and non parametric data by Kruskal Wallis test. For categorical data analysis chi-square test was applied. A p value of $<0.05$ was considered to be significant. ICU $=$ Intensive Care Unit; Care $=$ Nursing home care.

organ systems. Notably, the incidence of co-morbidities was significantly higher in the high dose statin group along with a higher age factor (Table 1). Despite the increased risk conferred by these co-morbidities, the inhospital outcome of the statin pre-treated group was the same as compared to non-statin group (Tables 3 and 4).

There was a higher requirement of dialysis in non statin group when compared with low/high dose statin groups. Pre-operative renal impairment was noted to be $27 \%$ (higher) in non statin group as compared to $17 \%$ and $14.5 \%$ in low/high dose statin groups. This explains why more patients in non statin group $(15 \%)$ required dialysis post operatively.

Challenging patients with post cardiac surgery systemic inflammatory response and ischemia-reperfusion injury can create dramatic increases in post-operative multi-organ dysfunction or failure. Our study shows reduced neutrophil migration and inflammatory markers like TNF- $\alpha$ and sICAM-1 with the use of statins. Therefore, we suggest that the benefits of statins outweigh their reversible sideeffects and so they may be used pre-operatively in selective patients undergoing cardiac surgery, to reduce the inflammatory response leading to better outcome.

\section{Acknowledgements}

Cardiothoracic Unit of Mater Misericordiae University Hospital, Dublin and Conway Institute, University College Dublin.

\section{REFERENCES}

[1] L. H. Edmunds Jr., "Inflammatory Response to Cardiopulmonary Bypass," The Annals of Thoracic Surgery, Vol. 66, No. 5, 1998, pp. S12-S16. doi:10.1016/S0003-4975(98)00967-9

[2] J. R. S. Day and K. M. Taylor, "The Systemic Inflammatory Response Syndrome and Cardiopulmonary Bypass,"
International Journal of Surgery, Vol. 3, No. 2, 2005, pp. 129-140. doi:10.1016/i.ijsu.2005.04.002

[3] N. C. Cavarocchi, M. D. England, H. V. Schaff, P. Russo, T. A. Orszulak, W. A. Schnell Jr., et al., "Oxygen Free Radical Generation during Cardiopulmonary Bypass: Correlation with Complement Activation," Circulation, Vol. 74, No. 5, 1986, pp. III130-III133.

[4] V. Niggli, "Microtubule-Disruption-Induced and Chemotactic-Peptide-Induced Migration of Human Neutrophils: Implications for Differential Sets of Signalling Pathways,' Journal of Cell Science, Vol. 116, Pt. 5, 2003, pp. 813822. doi: $10.1242 /$ jcs.00306

[5] B. M. Maher, T. N. Dhonnchu, J. P. Burke, A. Soo, A. E. Wood and R. W. G. Watson, "Statins Alter Neutrophil Migration by Modulating Cellular Rho Activity-A Potential Mechanism for Statins-Mediated Pleotropic Effects?" Journal of Leukocyte Biology, Vol. 85, No. 1, 2009, pp. 186-193. doi:10.1189/jlb.0608382

[6] N. Chalasani, "Statins and Hepatotoxicity: Focus on Patients with Fatty Liver," Hepatology, Vol. 41, No. 4, 2005, pp. 690-695. doi:10.1002/hep.20671

[7] The Long-Term Intervention with Pravastatin in Ischaemic Disease (LIPID) Study Group, "Prevention of Cardiovascular Events and Death with Pravastatin in Patients with Coronary Heart Disease and a Broad Range of Initial Cholesterol Levels," The New England Journal of Medicine, Vol. 339, No. 19, 1998, pp. 1349-1357. doi:10.1056/NEJM199811053391902

[8] L. L. Clark, J. S. Ikonomidis, F. A. Crawford Jr., A. Crumbley 3rd, J. M. Kratz, M. R. Stroud, et al., "Preoperative Statin Treatment Is Associated with Reduced PostOperative Mortality and Morbidity in Patients Undergoing Cardiac Surgery: An 8-Year Retrospective Cohort Study," The Journal of Thoracic and Cardiovascular Surgery, Vol. 131, No. 3, 2006, pp. 679-685. doi:10.1016/i.jtcvs.2005.11.006

[9] J. S. Pober, "Effects of Tumour Necrosis Factor and Related Cytokines on Vascular Endothelial Cells," Ciba Foundation Symposium, Vol. 131, 1987, pp. 170-184.

[10] G. J. Blake and P. M. Ridker, "Novel Clinical Markers of 
Vascular Wall Inflammation," Circulation Research, Vol. 89, No. 9, 2001, pp. 763-771. doi:10.1161/hh2101.099270

[11] J. S. Pober, M. A. Gimbrone Jr., L. A. Lapierre, D. L. Mendrick, W. Fiers, R. Rothlein and T. A. Springer, "Overlapping Patterns of Activation of Human Endothelial Cells by Interleukin 1, Tumor Necrosis Factor, and Immune Interferon," Journal of Immunology, Vol. 137, No. 6, 1986, pp. 1893-1896.

[12] A. Rezaie-Majd, G. W. Prager, R. A. Bucek, G. H. Schernthaner, T. Maca, H.-G. Kress, et al., "Simvastatin Reduces the Expression of Adhesion Molecules in Circulating Monocytes from Hypercholesterolemic Patients," Arteriosclerosis, Thrombosis, and Vascular Biology, Vol. 23, No. 3, 2003, pp. 397-403. doi:10.1161/01.ATV.0000059384.34874.F0

[13] L. M. Blanco-Colio, J. L. Martin-Ventura, E. de Teresa, C. Farsang, A. Gaw, G. Gensini, et al., "Elevated ICAM-1 and MCP-1 Plasma Levels in Subjects at High Cardiovascular Risk Are Diminished by Atorvastatin Treatment. Atorvastatin on Inflammatory Markers Study: A Substudy of Achieve Cholesterol Targets Fast with Atorvastatin Stratified Titration," American Heart Journal, Vol. 153, No. 5, 2007, pp. 881-888. doi:10.1016/j.ahj.2007.02.029

[14] A. J. Mackarel, K. J. Russell, C. S. Brady, M. X. FitzGerald and C. M. O'Connor, "Interleukin- 8 and LeukotrieneB(4), But Not Formylmethionyl Leucylphenylalanine, Stimulate CD18-Independent Migration of Neutrophils Across Human Pulmonary Endothelial Cells in Vitro," American Journal of Respiratory Cell and Molecular Bi- ology, Vol. 23, No. 2, 2000, pp. 154-161.

[15] F. Roques, S. A. Nashef, P. Michel, E. Gauducheau, C. de Vincentiis, E. Baudet, et al., "Risk Factors and Outcome in European Cardiac Surgery: Analysis of the EuroSCORE Multinational Database of 19030 Patients," European Journal of Cardio-Thoracic Surgery, Vol. 15, No. 6, 1999, pp. 816-822.

[16] J. H. Levy and K. A. Tanaka, "Inflammatory Response to Cardiopulmonary Bypass," The Annals of Thoracic Surgery, Vol. 75, No. 2, 2003, pp. S715-S720. doi:10.1016/S0003-4975(02)04701-X

[17] L. M. Fedoruk, H. K. Wang, M. R. Conaway, I. L. Kron and K. C. Johnston, "Statin Therapy Improves Outcomes after Valvular Heart Surgery," The Annals of Thoracic Surgery, Vol. 85, No. 5, 2008, pp. 1521-1526. doi:10.1016/j.athoracsur.2008.01.078

[18] A. Kinsella, A. Raza, S. Kennedy, Y. Fan, A. E. Wood and R. W. Watson, "The Impact of High-Dose Statin Therapy on Transendothelial Neutrophil Migration and Serum Cholesterol Levels in Healthy Male Volunteers," European Journal of Clinical Pharmacology, Vol. 67, No. 11, 2011, pp. 1103-1108. doi:10.1007/s00228-011-1062-Z

[19] M. Noutsias, C. Hohmann, M. Pauschinger, P.-L. Schwimmbeck, K. Ostermann, U. Rode, et al., "sICAM-1 Correlates with Myocardial ICAM-1 Expression in Dilated Cardiomyopathy," International Journal of Cardiology, Vol. 91, No. 2, 2003, pp. 153-161. doi:10.1016/S0167-5273(03)00033-0 